\title{
ВЛИЯНИЕ ЭКОНОМИЧЕСКИХ СПЕЦИАЛИЗАЦИЙ СЕВЕРНОГО МАКРОРЕГИОНА НА РАЗВИТИЕ МАЛОГО И СРЕДНЕГО ПРЕДПРИНИМАТЕЛЬСТВА
}

\author{
(c) 2019 Ермолин Евгений Николаевич \\ аспирант \\ Федеральный исследовательский центр комплексного изучения Арктики \\ имени академика Н.П. Лавёрова РАН, Россия, Архангельск \\ E-mail: e.n.ermolin@yandex.ru
}

В статье на примере Северного макрорегиона дана оценка влияния экономических специализаций территорий на развитие малого и среднего предпринимательства. Исследуя причинно-следственные связи в экономической системе региона, а также данные официальной статистики, автор приходит к выводу о том, что с учетом специфики северных территорий доминирующее влияние крупного бизнеса на сектор МСП проявляется, прежде всего, в формировании соответствующего уровня доходов населения, обеспечивающего потребительский спрос, который, в свою очередь, является определенным катализатором развития для малого и среднего бизнеса.

Ключевые слова: Северный макрорегион, экономическая специализация макрорегиона, малое и среднее предпринимательство, потребительский рынок, доходы населения.

Северный макрорегион - это относительно новое понятие, которое закреплено в Стратегии пространственного развития РФ (далее Стратегия), принятой в феврале 2019 года. В северный макрорегион согласно Стратегии включены Архангельская область, Ненецкий автономный округ и Республика Коми [5].

В Стратегию включен перечень перспективных экономических специализаций субъектов РФ. Отметим, что из трех территорий Северного макрорегиона две (Республика Коми и Ненецкий автономный округ) имеют ярко выраженную специализацию по добыче полезных ископаемых: в структуре экономики Республики Коми она занимает 35,0\%, в Ненецком автономном округе $-74,5 \%$ (таблица 1). При этом экономика Архангельской области достаточно диверсифицирована [2].

Очевидно, что добыча полезных ископаемых, а также виды экономической деятельности, имеющие значительный вклад в ВРП территорий Северного макрорегиона, представлены в основном крупным бизнесом. В таком случае возникает вопрос - какова же роль малого и среднего предпринимательства в Северном макрорегионе? Обратимся к данным статистики.

Как отражено в таблице 2 в Северном макрорегионе по состоянию на 10 июня 2019 года насчитывается 68,7 тыс. субъектов МСП, большую часть которых составляют индивидуальные предприниматели (63\%) и юридические лица $(32,5 \%)$ со статусом «микро», то есть с численностью работников до 15 человек включительно. Данный состав вполне соотносится с общероссийским.

Отметим, что основную долю в численности субъектов МСП Северного макрорегиона составляют предприятия Архангельской области (56\%). На долю Республики Коми приходится $42 \%$, Ненецкий автономный округ $-2 \%$.

Динамика численности работников в малом и среднем предпринимательстве Северного макрорегиона с декабря 2016 года по июнь 2019 года показывает рост на 14,8\% (таблица 3). При этом лидирующее положение среди территорий Северного макрорегиона по численности работников МСП принадлежит Архангельской области.

Численность работников в малом и среднем предпринимательстве Северного макрорегиона составляет $1,3 \%$ от общероссийского. В дальнейшем к 2024 году согласно национальному проекту «Малое предпринимательство и поддержка индивидуальной предпринимательской инициативы» планируется увеличение численности занятых в сфере МСП. Однако, реальная демографическая ситуация не дает оснований для оптимистического прогноза роста численности трудоспособного населения [8].

Показательной является представленная на 


\section{Таблица 1. Валовой региональный продукт субъектов Северного макрорегиона} по видам экономической деятельности, \%

\begin{tabular}{|c|c|c|c|c|c|c|c|c|c|c|c|c|}
\hline \multirow{3}{*}{$\begin{array}{l}\text { Валовой региональный } \\
\text { продукт (валовая добавлен- } \\
\text { ная стоимость в основных } \\
\text { ценах) }\end{array}$} & \multicolumn{4}{|c|}{$\begin{array}{c}\text { Ненецкий автономный } \\
\text { округ }\end{array}$} & \multicolumn{4}{|c|}{ Республика Коми } & \multicolumn{4}{|c|}{ Архангельская область } \\
\hline & 2013 & 2014 & 2015 & 2016 & 2013 & 2014 & 2015 & 2016 & 2013 & 2014 & 2015 & 2016 \\
\hline & 100 & 100 & 100 & 100 & 100 & 100 & 100 & 100 & 100 & 100 & 100 & 100 \\
\hline \multicolumn{13}{|l|}{ в том числе: } \\
\hline $\begin{array}{l}\text { сельское хозяйство, охота и } \\
\text { лесное хозяйство }\end{array}$ & 0,4 & 0,4 & 0,5 & 0,3 & 1,5 & 1,8 & 1,9 & 1,9 & 4,2 & 4,3 & 4,1 & 4,6 \\
\hline рыболовство, рыбоводство & 0,6 & 0,7 & 0,6 & 0,6 & 0,0 & 0,0 & 0,0 & 0,0 & 1,8 & 2,4 & 2,5 & 2,5 \\
\hline добыча полезных ископаемых & 75,3 & 73,8 & 69,9 & 74,5 & 33,3 & 33,2 & 35,9 & 35,0 & 0,9 & 2,3 & 3,4 & 3,8 \\
\hline $\begin{array}{l}\text { обрабатывающие производ- } \\
\text { ства }\end{array}$ & 0,3 & 0,3 & 0,3 & 0,3 & 11,4 & 10,7 & 11,5 & 11,7 & 18,7 & 19,9 & 22,9 & 22,1 \\
\hline $\begin{array}{l}\text { производство и распределе- } \\
\text { ние электроэнергии, газа и } \\
\text { воды }\end{array}$ & 0,9 & 1,0 & 0,9 & 0,9 & 3,5 & 3,9 & 3,0 & 3,1 & 4,5 & 3,8 & 3,4 & 3,5 \\
\hline строительство & 8,5 & 10,3 & 14,3 & 9,9 & 11,7 & 11,1 & 8,1 & 10,0 & 5,3 & 6,0 & 3,9 & 4,5 \\
\hline $\begin{array}{l}\text { оптовая и розничная торгов- } \\
\text { ля; ремонт автотранспортных } \\
\text { средств, мотоциклов, быто- } \\
\text { вых изделий и предметов } \\
\text { личного пользования }\end{array}$ & 0,8 & 0,9 & 0,7 & 0,7 & 5,8 & 6,2 & 5,2 & 5,0 & 11,9 & 11,9 & 12,0 & 11,6 \\
\hline гостиницы и рестораны & 0,2 & 0,2 & 0,1 & 0,2 & 0,7 & 0,8 & 0,7 & 0,7 & 1,2 & 1,4 & 1,5 & 1,6 \\
\hline транспорт и связь & 5,4 & 5,0 & 5,6 & 6,4 & 9,9 & 8,9 & 9,3 & 8,6 & 18,3 & 15,9 & 15,1 & 15,5 \\
\hline финансовая деятельность & 0,0 & 0,0 & 0,0 & 0,0 & 0,2 & 0,1 & 0,1 & 0,2 & 0,3 & 0,2 & 0,2 & 0,3 \\
\hline $\begin{array}{l}\text { операции с недвижимым } \\
\text { имуществом, аренда и предо- } \\
\text { ставление услуг }\end{array}$ & 2,9 & 2,7 & 3,2 & 2,9 & 6,6 & 7,1 & 9,2 & 9,3 & 7,9 & 7,8 & 8,8 & 9,1 \\
\hline $\begin{array}{l}\text { государственное управле- } \\
\text { ние и обеспечение военной } \\
\text { безопасности; социальное } \\
\text { страхование }\end{array}$ & 2,0 & 2,0 & 1,6 & 1,4 & 6,5 & 6,7 & 6,2 & 6,0 & 10,3 & 9,9 & 8,9 & 8,6 \\
\hline образование & 1,0 & 1,0 & 0,9 & 0,8 & 3,4 & 3,5 & 3,3 & 3,1 & 5,1 & 4,9 & 4,4 & 4,1 \\
\hline $\begin{array}{l}\text { здравоохранение и предо- } \\
\text { ставление социальных услуг }\end{array}$ & 1,1 & 1,2 & 1,0 & 0,8 & 4,4 & 4,9 & 4,5 & 4,3 & 7,7 & 7,5 & 7,1 & 6,6 \\
\hline $\begin{array}{l}\text { предоставление прочих } \\
\text { коммунальных, социальных и } \\
\text { персональных услуг }\end{array}$ & 0,6 & 0,5 & 0,4 & 0,3 & 1,0 & 1,0 & 1,0 & 1,0 & 1,9 & 1,8 & 1,8 & 1,6 \\
\hline
\end{tabular}

Источник: составлено автором по данным Росстата http://www.gks.ru

Таблица 2. Количество предприятий МСП в Северном макрорегионе на 10 июня 2019 г.

\begin{tabular}{|l|c|c|c|c|c|}
\hline & РФ & $\begin{array}{c}\text { Северный } \\
\text { макрорегион }\end{array}$ & $\begin{array}{c}\text { Архангельская } \\
\text { область }\end{array}$ & $\begin{array}{c}\text { Республика } \\
\text { Коми }\end{array}$ & $\begin{array}{c}\text { Ненецкий авто- } \\
\text { номный округ }\end{array}$ \\
\hline Всего & 6206133 & 68732 & 38271 & 28976 & 1485 \\
\hline ЮЛ Микро & 2537766 & 22310 & 12239 & 9708 & 363 \\
\hline ЮЛ Малое & 219043 & 2375 & 1321 & 1007 & 47 \\
\hline ЮЛ Среднее & 18174 & 151 & 84 & 62 & 5 \\
\hline ИП Микро & 3404038 & 43300 & 24228 & 18014 & 1058 \\
\hline ИП Малое & 26796 & 586 & 391 & 183 & 12 \\
\hline ИП Среднее & 316 & 10 & 8 & 2 & 0 \\
\hline
\end{tabular}

Источник: составлено автором по данным Федеральной налоговой службы https://www.nalog.ru 
Таблица 3. Динамика численности работников МСП Северного макрорегиона с 10 декабря 2016 по 10 июня 2019 г., человек

\begin{tabular}{|c|c|c|c|c|c|}
\hline Дата & РФ & $\begin{array}{c}\text { Северный } \\
\text { макрорегион }\end{array}$ & $\begin{array}{c}\text { Архангельская } \\
\text { область }\end{array}$ & $\begin{array}{c}\text { Республика } \\
\text { Коми }\end{array}$ & $\begin{array}{c}\text { Ненецкий авто- } \\
\text { номный округ }\end{array}$ \\
\hline 10.06 .2019 & 15922438 & 211300 & 118410 & 92890 & нет данных \\
\hline 10.12 .2018 & 16130582 & 200227 & 113144 & 83431 & 3652 \\
\hline 10.12 .2017 & 15917053 & 188025 & 107816 & 76829 & 3380 \\
\hline 10.12 .2016 & 15696576 & 184135 & 105165 & 75594 & 3376 \\
\hline
\end{tabular}

Источник: составлено автором по данным Росстата и ФНС

рисунке 1 динамика за 2007-2017 годы поступления налогов от хозяйствующих субъектов, находящихся на специальных режимах налогообложения (ЕНВД, УСН, ЕСХН), так как эти режимы являются основными для малого и среднего бизнеса. Анализ этой динамики для Северного макрорегиона позволяет утверждать, что собираемость перечисленных видов налогов за представленный период увеличилась в 2,6 раза. При этом наибольший темп роста по налогам у Архангельской области, наименьший темп роста у Ненецкого автономного округа.

Например, сравнивая присутствие индивидуальных предпринимателей в различных секторах экономики Архангельской области и НАО, получим картину, представленную в таблице 4, которая показывает, что в обоих регионах значительная концентрация малого бизнеса наблюдается в сфере торговли.

Вообще говоря, приведенная выше статистика лишь в общих чертах отражает те или иные аспекты состояния и развития МСП. Как отмечено в [3], недостаток информации не позволяет установить прямые количественные связи между различными факторами, без чего невозможно адекватно оценить сам объект, не говоря уже о разработках прогнозов его состояния при разного рода воздействиях на него. Этот тезис как нельзя лучше характеризует ту информационную базу, которую на сегодняшний день мы имеем в отношении сектора МСП: данные о нем зачастую носят отрывочный характер с высокой долей латентной составляющей и не обладают кросс-секционной полнотой.

Поэтому выявление каких-либо прямых устойчивых количественных связей здесь достаточно проблематично. Тем не менее, современные методологии качественного анализа позволяют не только определять скрытые влияния, но и путем когнитивного моделирования выявлять их силу и значимость.

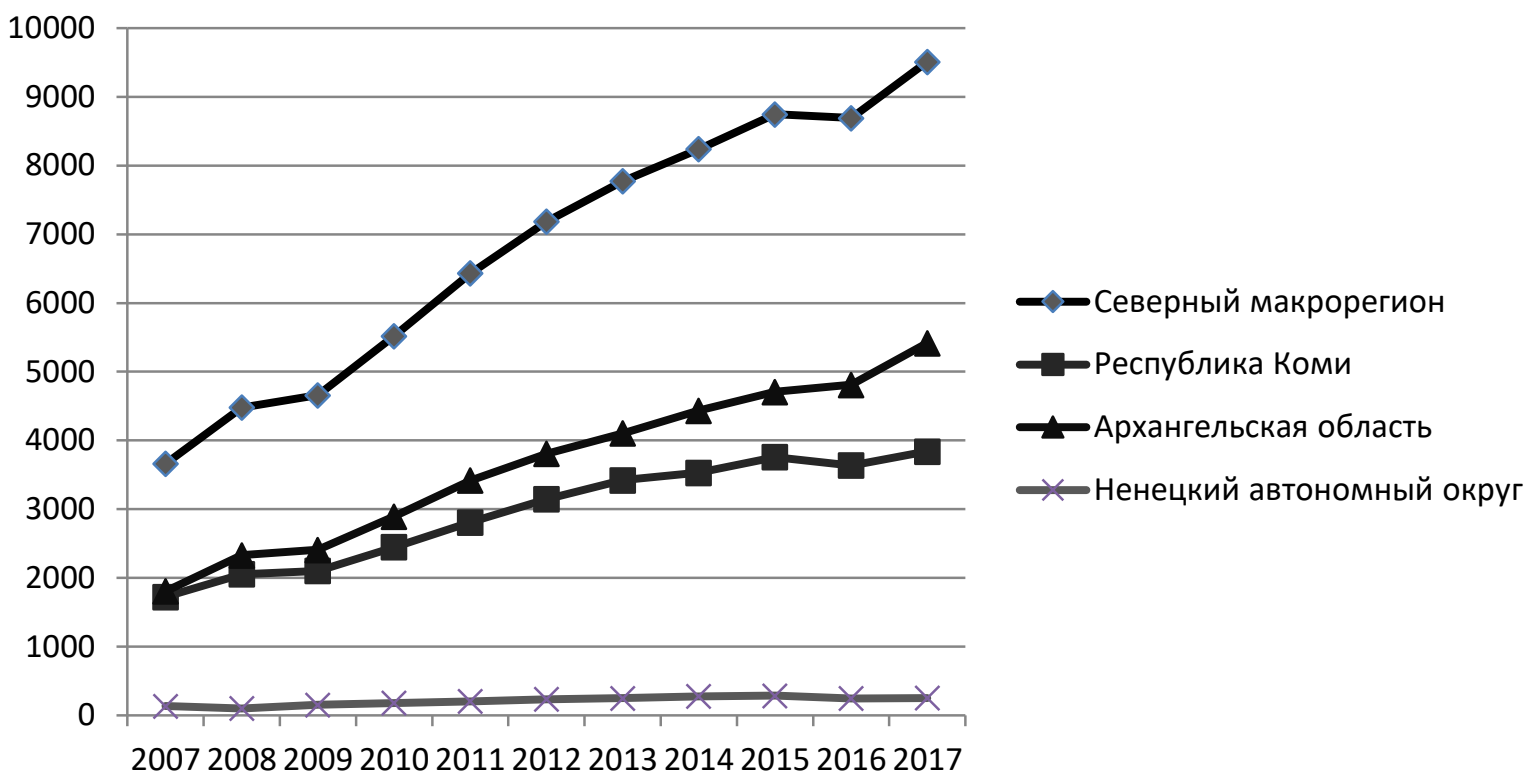

Puc. 1. Динамика налогов (ЕНВД, УСН, ЕСХН) по МСП Северного макрорегиона с 2007 по 2017 гг., млн. руб. Источник: составлено автором по данным Федеральной налоговой службы https://www.nalog.ru 
Таблица 4. Структура валового регионального продукта Архангельской области и Ненецкого автономного округа (НАО) по всем предприятиям и по индивидуальным предпринимателям в 2017 году

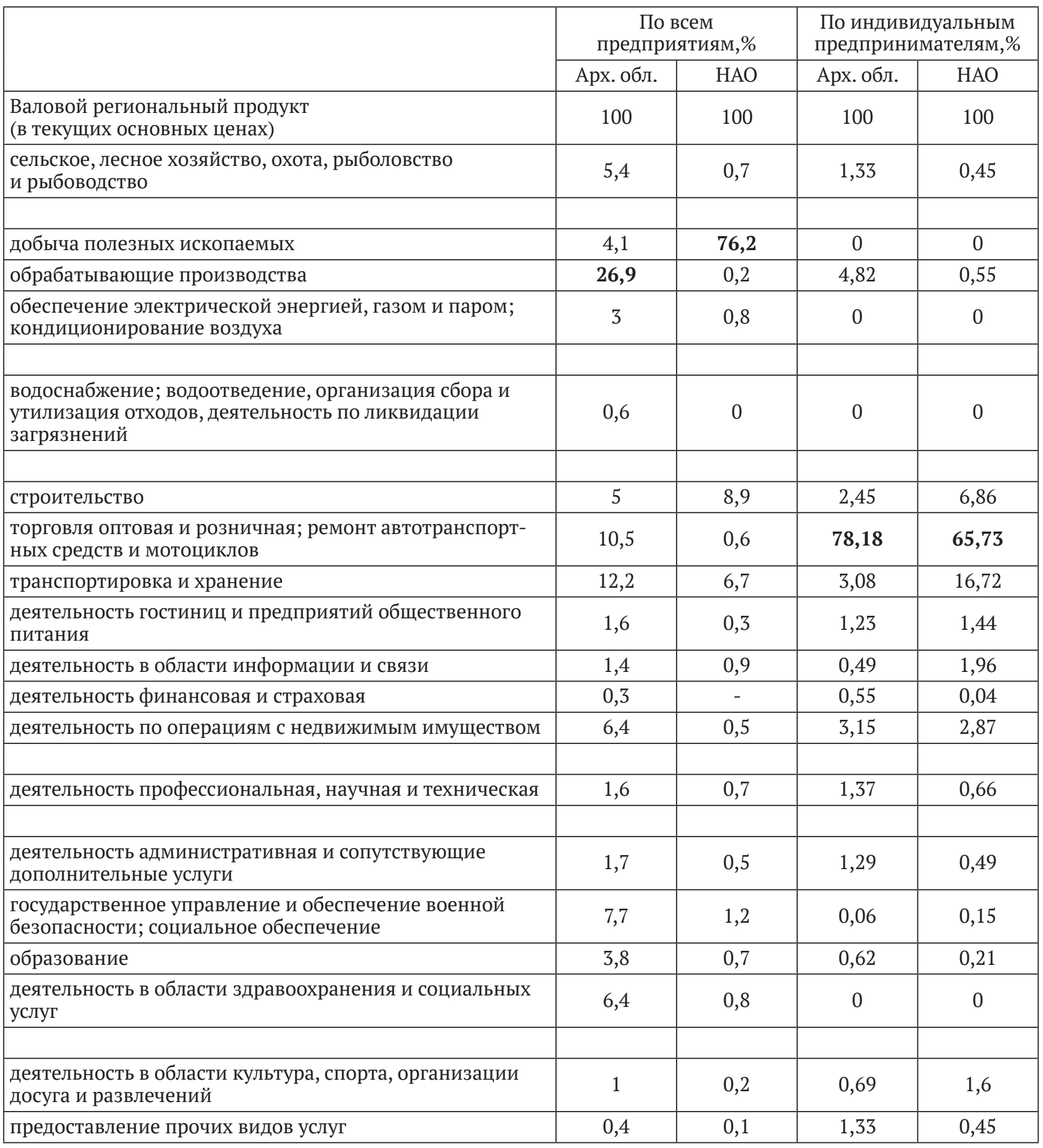

Источник: составлено автором по данным Росстата http://www.gks.ru 
В отношении сектора МСП соответствующая цепочка причинно-следственных связей представляется нам следующим образом: «доходы населения - платежеспособность - потребительский спрос - рынок товаров и услуг - активизация малого бизнеса - ...».

Теперь вопрос переходит в другую плоскость - за счет чего будут повышаться доходы населения и, как следствие, формироваться платежеспособный спрос. Другими словами - где население возьмет необходимый финансовый ресурс? Попробуем ответить на этот вопрос хотя бы в рамках одного специфического макрорегиона.

Согласно теории сбалансированного роста, именно увеличение общего спроса является основой его устойчивости [4]. Небезосновательным будет и утверждение о том, что активность малого бизнеса существенно зависит от состояния местного потребительского рынка. Появление, ликвидация или межрегиональная миграция субъектов малых форм хозяйствования в значительной степени зависит от платежеспособного спроса населения. Таким образом, активность субъектов МСП на территориях фактически является откликом (возможно, несколько отложенным во времени) на потребительские настроения и ожидания населения (реально располагаемые доходы, готовность брать кредиты и займы, тратить либо накапливать сбережения и т.д.). Поэтому малый бизнес играет роль своеобразного барометра экономического благополучия населения на данной территории.

По данным исследований, проведенным Сбербанком [10] в апреле 2019 года, активность в сегменте малого и среднего предпринимательства (МСП) в России в 2019 году стабилизировалась после существенного роста в предыдущем периоде. При этом показатели динамики роста малого и среднего бизнеса, работающего напрямую с конечным потребителем, имели меньшие значения по сравнению с теми отраслями, где традиционно превалирует крупный бизнес, например, добывающая промышленность.

Отметим, что в Республике Коми и Архангельской области, так и по Северному макрорегиону в целом, удельный показатель числа активных компаний существенно ниже общероссийского уровня, при этом наблюдается, хотя и незначительный, отток бизнеса в другие регионы (таблица 5).

На этом фоне выделяется Ненецкий автономный округ - среди всех субъектов РФ он является регионом с минимальной долей компаний МСП в таком секторе, как оптовая и розничная торговля $-27,95 \%$ (в среднем по РФ этот показатель составляет 36,51\%). Неразвитость торговли, доля которой в ВРП округа составляет менее $1 \%$, во многом объясняется малой численностью населения, его крайне низкой плотностью и отсутствием наземной транспортной инфраструктуры - в НАО нет железнодорожного сообщения и автомобильных дорог круглогодичного действия, а основными видами транспорта являются морской и авиационный. Они в значительной степени обеспечивают население продуктами питания и товарами народного потребления, в том числе, в рамках «северного завоза» [1].

Вернемся к экономическим специализациям Северного макрорегиона, указанным в Стратегии пространственного развития РФ. Посмотрим насколько сектор МСП укладывается в общие рамки региональных экономических профилей. При этом отметим, что профили экономических специализаций этих регионов также имеют существенные отличия.

\section{Таблица 5. Активность субъектов МСП в Северном макрорегионе}

\begin{tabular}{|c|c|c|c|c|}
\hline \multirow{2}{*}{$\begin{array}{c}\text { Субъекты РФ, входящие } \\
\text { в Северный макроре- } \\
\text { гион }\end{array}$} & \multicolumn{2}{|c|}{$\begin{array}{l}\text { Количество на } 1000 \text { чел. населения в } \\
\text { трудоспособном возрасте и старше* }\end{array}$} & \multirow{2}{*}{$\begin{array}{c}\text { Изменение числа } \\
\text { активных компа- } \\
\text { ний }^{* * *}\end{array}$} & \multirow{2}{*}{$\begin{array}{c}\text { Чистый приток ак- } \\
\text { тивных компаний } \\
\text { из других регио- } \\
\text { нов }^{* * * *}\end{array}$} \\
\hline & $\begin{array}{l}\text { активных } \\
\text { компаний }\end{array}$ & предпринимателей & & \\
\hline Республика Коми & 25,29 & 25,99 & $-1,46 \%$ & $-0,43 \%$ \\
\hline Архангельская обл. & 23,84 & 24,81 & $3,63 \%$ & $-0,34 \%$ \\
\hline Ненецкий АО & 27,19 & 31,42 & $1,05 \%$ & $0,32 \%$ \\
\hline Северный макрорегион & 24,51 & 25,44 & $1,45 \%$ & $-0,36 \%$ \\
\hline РФ в среднем & 27,64 & 28,55 & $0,26 \%$ & - \\
\hline
\end{tabular}

* - в данной категории населения Северного макрорегиона доля Республики Коми составляет 41,7\%, Архангельской области $-56,2 \%$, HAO $-2,1 \%$

** - март 2019 г. к августу 2018 г.

*** - от числа активных в данном регионе в 2017 г. 
Составим матрицу следующих показателей (таблица 6):

$x_{i j}=\left\{\begin{array}{c}1, \text { если специализация } i \text { отнесена к перспективным в регионе } j \\ -1, \text { если специализация } i \text { отнесена к неперспективным в регионе } j \\ 0, \text { если специализация } i \text { в регионе } j \text { отсутствует }\end{array}\right.$

Таблица 6. Матрица экономических специализаций Северного макрорегиона [2]

\begin{tabular}{|c|c|c|c|c|}
\hline \multirow{2}{*}{$i$} & \multirow{2}{*}{ Экономические специализации регионов } & \multicolumn{3}{|c|}{$j=1,2,3$} \\
\hline & & Арх. обл. & Респ. Коми & HAO \\
\hline 1 & добыча полезных ископаемых & 1 & 1 & 1 \\
\hline 2 & лесоводство и лесозаготовка & 1 & 1 & 0 \\
\hline 3 & обработка древесины и производство изделий из дерева & 1 & 1 & 0 \\
\hline 4 & производство бумаги и бумажных изделий & 1 & 1 & 0 \\
\hline 5 & производство кокса и нефтепродуктов & 0 & 1 & 0 \\
\hline 6 & $\begin{array}{l}\text { производство готовых металлических изделий, кроме машин и } \\
\text { оборудования }\end{array}$ & 1 & 0 & 0 \\
\hline 7 & $\begin{array}{l}\text { производство машин и оборудования, не включенных в другие } \\
\text { группировки }\end{array}$ & 1 & 1 & 0 \\
\hline 8 & производство пищевых продуктов & 1 & -1 & 0 \\
\hline 9 & производство прочей неметаллической минеральной продукции & 1 & 0 & 0 \\
\hline 10 & производство прочих готовых изделий & 1 & 1 & 1 \\
\hline 11 & производство прочих транспортных средств и оборудования & 1 & 0 & 0 \\
\hline 12 & производство резиновых и пластмассовых изделий & 1 & 0 & 0 \\
\hline 13 & производство химических веществ и химических продуктов & 1 & 0 & 0 \\
\hline 14 & производство электрического оборудования & 1 & 0 & 0 \\
\hline 15 & производство текстильных изделий & 0 & -1 & 0 \\
\hline 16 & рыболовство и рыбоводство & 1 & 0 & -1 \\
\hline 17 & деятельность в области информации, связи & 1 & 0 & 1 \\
\hline 18 & деятельность профессиональная, научная и техническая & 1 & 0 & 0 \\
\hline 19 & транспортировка и хранение & 1 & 1 & 1 \\
\hline 20 & туризм & 1 & 1 & 0 \\
\hline 21 & растениеводство и животноводство & -1 & -1 & -1 \\
\hline
\end{tabular}

Данная матрица позволяет представить степени различия между регионами с точки зрения перспективных и неперспективных специализаций.

Если для Архангельской области в ее профиль включено 18 перспективных специализаций из общего числа 21 присутствующих в макрорегионе в целом (86\%), то для Республики Коми их всего 9 (43\%), а для НАО - только 4 (19\%). При этом из общего Перечня специализаций, как перспективных, так и неперспективных, во всех трех субъектах их отмечено только 4 (19\%), в двух субъектах -8 (38\%), только в одном субъекте - 9 (43\%). Общими специализациями, перспективными для всего Северного макрорегиона, являются «Добыча полезных ископаемых», «Производство прочих готовых изделий» и «Транспортировка и хранение». Общей же неперспективной экономической специализацией, критически важной для всех трех регионов, является «Растениеводство и животноводство» [2].

Таким образом, экономические специализации Северного макрорегиона скорее определяют сферу интересов крупного бизнеса, а МСП занимает другие ниши (торговля, общественное питание, бытовые услуги, местный транспорт и т.д.). Поэтому можно констатировать, что системообразующие экономические тренды оказывают не прямое, а лишь опосредованное влияние на малый и средний бизнес, основным фактором развития которого выступает платежеспособный спрос населения, реализуемый через потребительский рынок и сферу услуг. Учитывая, что основная часть доходов населения формируется за счет заработной платы работников крупных предприятий и бюджетной сферы, роль последних для развития сектора МСП заключается в создании высокопроизводительных и вы- 
сокооплачиваемых рабочих мест. Проще говоря, достойный уровень заработной платы работников, в первую очередь на крупных предприятиях, является фундаментом для формирования платежеспособного спроса населения.

Отметим, что в Северном макрорегионе имеется существенное превышение уровня заработной платы на предприятиях добывающей отрасли над средним показателем по субъекту РФ: в Архангельской области оно составляет 1,88 раза, в Республике Коми - 1,83 и в Ненецком автономном округе $-1,35$. При этом заработная плата в таких традиционных для малого бизнеса отраслях, как торговля, общественное питание, бытовые услуги, значительно ниже среднего уровня и составляет от него порядка 50-60\%.

Таким образом, считаем, что на текущий момент времени доходы населения выступают единственным рычагом развития МСП региона. Если у населения нет достаточного объема денежных средств для развития МСП территории (это проблема малых и территориально удаленных пунктов), тогда, на наш взгляд, уместно развивать такие виды деятельности, которые смогут привлекать население других регионов, а соответственно и их финансовые ресурсы (дохо- ды).

МСП должно занимать те ниши, которые не обеспечиваются товарами и услугами со стороны крупного бизнеса, но востребованы населением. Очевидно, что в реалиях список востребованных видов деятельности МСП не будет совпадать с экономическими приоритетами Северного макрорегиона. Это может объясняться, в том числе и тем, что «..региональные особенности играют в формировании и поведении бизнес-сообществ не меньшую, а зачастую, превалирующую роль по сравнению с общими тенденциями» $[6,7]$.

Как отмечено в работе [9], несбалансированность экономической ситуации требует разработки и реализации системных стратегических решений как на федеральном уровне, так и на уровне отдельных регионов, и хозяйствующих субъектов.

Поэтому считаем, что для обеспечения сбалансированного развития экономики Северного макрорегиона задачи государства должны сводиться к созданию условий для: роста доходов населения (в том числе за счет докапитализации населения); развитию конкуренции в сфере МСП; использования институтами развития типовых моделей местных (локальных) экономик.

\section{Библиографический список}

1. Антипов Е.О., Тутыгин А.Г., Коробов В.Б. Проблемы осуществления транспортировки грузов в Арктической зоне РФ морским путем // Управленческое консультирование. 2017. № 11 (107). С. 72-79.

2. Ермолин Е.Н. Различие экономических специализаций территорий северного макрорегиона // Государство и бизнес. Экосистема цифровой экономики: материалы ХІ Международной научно-практической конференции. Санкт-Петербург, 24-26 апреля 2019 г. / Северо-Западный институт управления РАНХиГС при Президенте РФ. С. 255-258.

3. Коробов В.Б. Теория и практика экспертных методов: монография / В.Б. Коробов; под ред. Б.И. Кочурова.М. ИНФРА-М, 2019.- 281 с.

4. Курзенев В., Матвеенко В. Экономический рост.- СПб.: Питер, 2018.-608 с.

5. Стратегия пространственного развития Российской Федерации (утверждена распоряжением Правительства Российской Федерации 13 февраля 2019 года № 207-р)

6. Тутыгин А.Г., Коробов В.Б., Чижова Л.А., Малинина К.О. Бизнес-сообщество Русского Севера: модели поведения: монография.- Ростов-н/Д.: Легион-М, 2018. - 244 с.

7. Тутыгин А.Г., Чижова Л.А. Моделирование траектории поведения локальных бизнес-сообществ в условиях Русского Севера // Экономические науки. 2018. № 9 (166). С. 28-38. DOI: 10.14451/1.166.28

8. Тутыгин А.Г., Чижова Л.А., Ананьина О.В. Увеличение численности занятых в малом бизнесе - системная проблема или достижимый результат? // Государство и бизнес. Экосистема цифровой экономики: материалы XI Международной научно-практической конференции. Санкт-Петербург, 24-26 апреля 2019 г. / Северо-Западный институт управления РАНХиГС при Президенте РФ. Том 2. С. 191-196.

9. Тутыгин А.Г., Чижова Л.А. Экономический рост и уровень жизни населения: проблема сбалансированности в стратегиях социально-экономического развития регионов Арктической зоны РФ // Управление инновационным развитием Арктической зоны Российской Федерации. Сборник избранных трудов по материалам Всероссийской научно-практической конференции с международным участием. Составители Е.Н. Богданова, И.Д. Нефедова. 2017. С. 131-136.

10. Развитие малого и среднего бизнеса в России. Апрель, 2019 г. https://www.sberbank.ru/common/img/ uploaded/files/pdf/analytics/s_m_business_dev.pdf 